\title{
SCGB2A2 Positive
}

National Cancer Institute

\section{Source}

National Cancer Institute. SCGB2A2 Positive. NCI Thesaurus. Code C141407.

An indication that SCGB2A2 expression has been detected in a sample. 